\title{
Pentoxifylline Inhibits Platelet-Derived Growth Factor- Stimulated Cyclin D1 Expression in Mesangial Cells by Blocking Akt Membrane Translocation
}

\author{
SHUEI-LIONG LIN, RUEY-HWA CHEN, YUNG-MING CHEN, WEN-CHIH CHIANG, TUN-JUN TSAI, and \\ BOR-SHEN HSIEH
}

Department of Internal Medicine, National Taiwan University Hospital (S.-L.L., Y.-M.C., W.-C.C., T.-J.T., B.-S.H.); and Department of Medicine (S.-L.L., Y.-M.C., W.-C.C., T.-J.T., B.-S.H.), Institute of Molecular Medicine (R.-H.C.), and Graduate Institute of Clinical Medicine (S.-L.L., W.C.C.), College of Medicine, National Taiwan University, Taipei, Taiwan

Received March 6, 2003; accepted June 26, 2003

This article is available online at http://molpharm.aspetjournals.org

\begin{abstract}
Pentoxifylline (PTX) is a potent inhibitor of mesangial cell proliferation, but its underlying mechanism is poorly understood. Here, we demonstrate that in platelet-derived growth factor (PDGF)-stimulated mesangial cells, PTX causes $\mathrm{G}_{1}$ arrest by down-regulation of cyclin D1 expression, which subsequently attenuates Cdk4 activity. In vivo, PTX similarly reduces cyclin D1 expression in mesangial cells of rats with acute Thy1 glomerulonephritis. The mechanism by which PTX reduces cyclin D1 is also investigated. PTX blocks Akt but not phosphatidylinositol 3-kinase (PI3K) activation in response to PDGF and abrogates cyclin D1 induction by PI3K, suggesting an effect of PTX on Akt itself. Indeed, PTX is capable of blocking the membrane translocation of Akt, and enforced targeting of Akt
\end{abstract}

to cell membrane prevents the inhibition of Akt and cyclin D1 by PTX. Because PTX is known to increase intracellular cAMP levels by inhibiting phosphodiesterase, the role of protein kinase $A(P K A)$ in these events is investigated. The PKA antagonist $N$-[2-(4-bromocinnamylamino)ethyl]-5-isoquinoline (H89) abolishes cell proliferation effects of PTX and restores cyclin D1 expression as well as Akt membrane translocation and activation by PDGF, whereas dibutyryl CAMP and forskolin recapitulate the functions of PTX in mesangial cells. In conclusion, our results indicate that PTX, acting through PKA, interferes with PDGF signaling to Akt activation by blocking Akt membrane translocation, thereby inhibiting cyclin D1 expression and mesangial cell proliferation.
Pentoxifylline (PTX), a phosphodiesterase inhibitor, effectively decreases the proteinuria of patients with diabetic or membranous nephropathy (Navarro et al., 1999; Duclous et al., 2001). In accordance with this clinical effect, we have previously shown that PTX attenuates experimental mesangial proliferative glomerulonephritis and progressive chronic renal disease (Chen et al., 1999b; Lin et al., 2002). One possible mechanism responsible for the renoprotection may be linked to the effect of PTX against glomerular mesangial cell proliferation. Indeed, PTX inhibits mesangial cell prolif-

This study was supported by grants from the National Science Council (NSC-91-2314-B-002-347), National Taiwan University Hospital (NTUH-90N), Ta-Tung Kidney Foundation, and Mrs. Hsiu-Chin Lee Kidney Research Foundation.

This work was previously presented in abstract form at the Annual Meeting of Taiwan Society of Nephrology in 2002. eration in vitro and in vivo (Tsai et al., 1995; Chen et al., 1999b). Although we previously found that PTX inhibits vascular smooth muscle cell proliferation through cAMP/PKA (Chen et al., 1999c), the detailed mechanism by which PTX suppresses mesangial cell proliferation is not known.

PDGF is generally believed to be a crucial growth factor for mesangial cell proliferation. However, PDGF also plays an important role in the pathogenesis of mesangial proliferative glomerular disease. Specific antagonism of PDGF reduces mesangial cell proliferation and glomerulosclerosis in experimental mesangial proliferative glomerular disease (Johnson et al., 1992; Floege et al., 1999; Gilbert et al., 2001; Ostendorf et al., 2001). Furthermore, PDGF antagonism therapy causes little toxicity in experimental renal diseases as well as tumor patients (Schindler et al., 2000; Gilbert et al., 2001). Therefore, PTX-induced inhibition of PDGF-stimulated mesangial

ABBREVIATIONS: PTX, pentoxifylline; PKA, protein kinase A; MAPK, mitogen-activated protein kinase; PI3K, phosphatidylinositol 3-kinase; Cdk, cyclin-dependent kinase; HA, hemagglutinin; GSK3 $\beta$, glycogen synthase kinase $3 \beta$; PDGF, platelet-derived growth factor; CREB, cAMP response element binding protein; MTT, 3-[4,5-dimethylthiazol-2-yl]-2,5-diphenyltetrazolium bromide; db-cAMP, dibutyryl cAMP; FK, forskolin; IBMX, 3-isobutyl-1-methylxanthine; H89, N-[2-(4-bromocinnamylamino)ethyl]-5-isoquinoline; BrdU, 5-bromo-2'-deoxyuridine; Hoechst 33258, 2p-(4hydroxyphenyl)-5-(4-methyl-1-piperazinyl)-2,5p-bi-benzimidazole; PBS, phosphate-buffered saline; EGFP, enhanced green fluorescent protein; $\mathrm{Rb}$, retinoblastoma; TUNEL, terminal deoxynucleotidyl transferase dUTP nick-end labeling; APH, aphidicolin; LY294002, 2-(4-morpholinyl)-8phenyl-1(4H)-benzopyran-4-one hydrochloride; PD98059, 2'-amino-3'-methoxyflavone; GFP, green fluorescent protein. 
cell proliferation represents an excellent strategy for ameliorating the renal disease. Because PTX alters neither PDGF binding to receptor nor receptor phosphorylation (Pinzani et al., 1996; Peterson et al., 2002), a possible mechanism for its inhibitory effect on PDGF-stimulated proliferation is the inhibition of PDGF postreceptor signaling. Indeed, PTX has been found to inhibit PDGF-induced activation of mitogenactivated protein kinase (MAPK) pathway (Pinzani et al., 1996; Peterson et al., 2002).

Both MAPK and phosphatidylinositol 3-kinase (PI3K) pathways transmit PDGF signaling to regulate the expression of cyclins and cyclin-dependent kinase (Cdk) inhibitors, thereby activating $\mathrm{Cdk}$ to promote cell cycle progression (Cheng et al., 1998; Diehl et al., 1998; Jones et al., 1999; Choudhury, 2001; Jones and Kazlauskas, 2001). Accordingly, activation of mesangial cell proliferation has been shown to be associated with up-regulation of cyclin D1 and downregulation of $\mathrm{p} 27^{\text {Kip } 1}$ (Shankland et al., 1996, 1997; Terada et al., 1998; Lang et al., 2000). PI3K and its downstream effector Akt have been demonstrated to mediate p27 ${ }^{\text {Kip } 1}$ downregulation induced by PDGF (Choudhury, 2001). The pathway that is responsible for cyclin D1 induction in mesangial cells, however, has not been defined. Whether PTX inhibits PDGF postreceptor signaling pathways, thereby inhibiting mesangial cell proliferation, is not clear.

In this study, we investigated the mechanism by which PTX inhibits proliferation in PDGF-stimulated mesangial cells. Our results indicate that PTX arrested PDGF-stimulated mesangial cells in the mid- $\mathrm{G}_{1}$ phase. We then found that PTX down-regulated cyclin D1 expression not only in vitro in cultured mesangial cells, but also in vivo in mesangial cells of rats with acute Thy1 glomerulonephritis. We further demonstrated that PTX, acting through PKA, interfered with PDGF signaling to Akt by blocking Akt membrane targeting, thereby inhibiting cyclin D1 expression and mesangial cell proliferation.

\section{Materials and Methods}

Antibodies. Antibodies against $\beta$-actin and hemagglutinin (HA) were purchased from Sigma (Saint Louis, MO). Antibodies against cyclin D1, total Akt1/2 (Akt), and fluorescein- and rhodamine-conjugated antibodies were purchased from Santa Cruz Biotechnology (Santa Cruz, CA). Antibodies against Cdk4 (clone DCS-35) and glycogen synthase kinase $3 \beta$ (GSK3 $\beta$ ) were from BD Transduction Laboratories (Lexington, KY). Antibodies against Thr308-phosphorylated Akt [p-Akt (Thr308)], Ser473-phosphorylated Akt [p-Akt (Ser473)], Ser780-phosphorylated retinoblastoma [p-Rb (Ser780)], Ser9-phosphorylated GSK3 $\beta$ (p-GSK3 $\beta$ ), and Ser 21/9-phosphorylated GSK $3 \alpha / \beta$ (p-GSK3 $\alpha / \beta$ ) were from Cell Signaling Technology (Beverly, MA). Antibodies against Ser133-phosphorylated cAMP response element binding protein ( $\mathrm{p}$-CREB) and phosphotyrosine (clone 4G10) were from Upstate Biotechnology (Lake Placid, NY). Antibody against Thy1 antigen was from Serotec (Oxford, United Kingdom).

Rat Mesangial Cell Culture and Transfection. Rat mesangial cells were cultured and identified as stated previously (Tsai et al., 1995). Mesangial cells of passages 4 to 10 were used for experiments. Confluent cells were made growth-arrested by serum deprivation for $24 \mathrm{~h}$. For transient transfection, mesangial cells at $40 \%$ confluence were incubated for $8 \mathrm{~h}$ with $200 \mathrm{ng} / \mathrm{ml}$ of plasmid DNA and $4 \mu \mathrm{l} / \mathrm{ml}$ of Effectene transfection reagent (QIAGEN, Valencia, CA). Cells were then replaced with fresh medium and cultured for further $24 \mathrm{~h}$.
After serum deprivation for $24 \mathrm{~h}$, the cells were treated and harvested for RNA or protein extraction.

Assessment of Cell Proliferation, DNA Synthesis, and Cell Cycle Progression. A modified 3-[4,5-dimethylthiazol-2-yl]-2,5-diphenyltetrazolium bromide (MTT) assay was used to measure cell proliferation as described previously (Tsai et al., 1995). Growtharrested cells were stimulated with recombinant rat PDGF-BB (PDGF, $20 \mathrm{ng} / \mathrm{ml}$; R\&D Systems, Minneapolis, MN) in the presence of PTX (Sigma), dibutyryl cAMP (db-cAMP), forskolin (FK), 3-isobutyl-1-methylxanthine (IBMX), H89 (Calbiochem, San Diego, CA), or vehicle. Final 10\% MTT was added into each well, and the absorbance at $570 \mathrm{~nm}$ was measured with an enzyme-linked immunosorbent assay reader. To assess DNA synthesis, $10 \mu \mathrm{M}$ 5-bromo-2'deoxyuridine (BrdU) (Roche, Mannheim, Germany) was added into the medium in the last hour of incubation. After fixation in $4 \%$ paraformaldehyde, cells were incubated with anti-BrdU monoclonal antibody with nuclease for $30 \mathrm{~min}$ at $37^{\circ} \mathrm{C}$. Then the cells were covered with fluorescein-conjugated anti-mouse antibody for $30 \mathrm{~min}$ at room temperature, counter-stained with Hoechst $33258(1 \mu \mathrm{g} / \mathrm{ml}$, Sigma), and examined by fluorescence microscopy. At least 200 cells were counted per experiment, and the results were expressed as percentage of BrdU-labeled nuclei. To determine cell cycle progression, flow cytometry analysis of DNA content was used as described previously (Chen et al., 1999c).

Apoptosis Assay. Growth-arrested mesangial cells were stimulated with PDGF in the presence of vehicle or PTX for $24 \mathrm{~h}$. TUNEL assay used to examine the percentage of cells undergoing apoptosis was performed using the in situ death detection kit with fluorescein (Roche) as described previously (Chen et al., 1998).

RNA and Protein Extraction and Northern and Western Blot Analyses. Total RNA was isolated by acid guanidinium thiocyanate-phenol-chloroform method, and Northern blot analysis was performed as described previously (Tsai et al., 1995). Cyclin D1 RNA probe was synthesized by reverse transcription-polymerase chain reaction with RNA from rat mesangial cells using the following primers: forward, 5' -ctgacaccaatctcctcaac-3' (corresponding to bases 178-197); reverse, 5'-gtagatgcacaacttctgg-3' (complementary to bases 506-487) (Tamura et al., 1993). The product was subcloned into the pGEM-dT vector (Promega, Madison, WI) for in vitro transcription of antisense digoxigenin-conjugated riboprobe.

Total cellular proteins were extracted by radioimmunoprecipitation assay buffer containing 1\% Igepal CA630, and nuclear proteins were obtained using methods described previously (Chen et al., 2003). Cellular fractions were prepared according to procedures described previously (Choudhury et al., 1997). The protein concentration was determined by Bio-Rad protein assay (Bio-Rad, Hercules, CA). Equal amounts of proteins were subjected to Western blot analysis as described previously (Chen et al., 2003).

Experimental Mesangial Proliferative Glomerulonephritis. Experimental mesangial proliferative glomerulonephritis was induced as described previously (Chen et al., 1999b). The nephritic rats received $250 \mu \mathrm{g}$ of a mouse anti-rat Thy 1 (CD90) monoclonal antibody (Cedarlane, Ontario, PQ, Canada) in $0.2 \mathrm{ml}$ of phosphate-buffered saline (PBS) at the beginning of day 0 and were treated with either vehicle (PBS, $n=6)$ or PTX $(0.1 \mathrm{~g} / \mathrm{kg} /$ day, $n=$ 6 ) from day 0 to day 5 . Normal control rats received only $0.2 \mathrm{ml}$ of PBS at the beginning of day $0(n=6)$. All rats were sacrificed at the end of day 5. Urine samples were aspirated from urinary bladders. One kidney was removed for preparing the glomerular RNA and protein and the other was cut into 4-mm slices for renal immunopathology. The animal care and treatment were conducted in accordance with the Guide for the Care and Use of Laboratory Animals as adopted and promulgated by the National Institutes of Health.

Renal Immunopathology. Briefly, renal sections were first microwaved in $0.01 \mathrm{M}$ citrate buffer, $\mathrm{pH} 6.0$, for $5 \mathrm{~min}$ at $800 \mathrm{~W}$, and then incubated with monoclonal antibody against Thy1 antigen, a surface marker of mesangial cells, and polyclonal antibody against 
cyclin $\mathrm{D} 1$ at $4^{\circ} \mathrm{C}$ overnight. After three washes in PBS/0.2\% Triton $\mathrm{X}-100$, the sections were incubated with fluorescein-conjugated antimouse antibody and rhodamine-conjugated anti-rabbit antibody and then examined by fluorescence microscopy. Cells positive for both Thy1 and cyclin D1 were counted in 25 glomeruli per rat in highpower microscopic fields $(400 \times)$. The average numbers per glomerulus were calculated and expressed as mean \pm S.D. for each group.

Plasmids. Mammalian expression vectors for the constitutively active form of PI3K (p110*) and the wild (HA-Akt), dominant-negative (HA-Akt-K179A), and myristoylated (HA-Akt-Myr) forms of Akt were from Dr. A Klippel (described in Chen et al., 1998). pEGFP-Akt was generated by polymerase chain reaction using the following primers: cggaattccgatgagcgacgtggctattgtg [a primer representing the Akt sense-strand sequence flanked by an EcoRI site (underlined) and containing an initiating codon (bold)]; cgggatccegggcegtgctgetggccgagta [a primer inversely complementary to the $3^{\prime}$ Akt sequence flanked by a Bam HI site (underlined)], followed by subcloning into the pEGFP-N1 (BD Biosciences Clontech, Palo Alto, CA).

Cdk4 and Akt Kinase Assays. Cdk4 activity was assayed essentially as described previously (Lang et al., 2000). Briefly, $500 \mu \mathrm{g}$ of total cellular extracts were immunoprecipitated with $2.5 \mu \mathrm{g}$ of antiCdk4 antibody, and the precipitates were incubated in the kinase buffer containing $200 \mu \mathrm{M}$ ATP and $1 \mu \mathrm{g}$ of Rb fusion protein (amino acids 769-921; Santa Cruz Biotechnology) at $30^{\circ} \mathrm{C}$ for $30 \mathrm{~min}$. Akt activity was assayed using the Akt kinase assay kit (Cell Signaling Technology). Briefly, $100 \mu \mathrm{g}$ of total cellular extracts were immunoprecipitated with anti-HA or anti-total Akt1/2 antibody, and the precipitates were incubated in the kinase buffer containing $200 \mu \mathrm{M}$ ATP and $1 \mu \mathrm{g}$ of GSK3 fusion protein at $30^{\circ} \mathrm{C}$ for $30 \mathrm{~min}$. For both kinase assays, the reactions were separated by SDS-polyacrylamide gel electrophoresis and analyzed by Western blot with antibody against $\mathrm{p}-\mathrm{Rb}(\mathrm{Ser} 780)$ or $\mathrm{p}-\mathrm{GSK} 3 \alpha / \beta$, respectively.
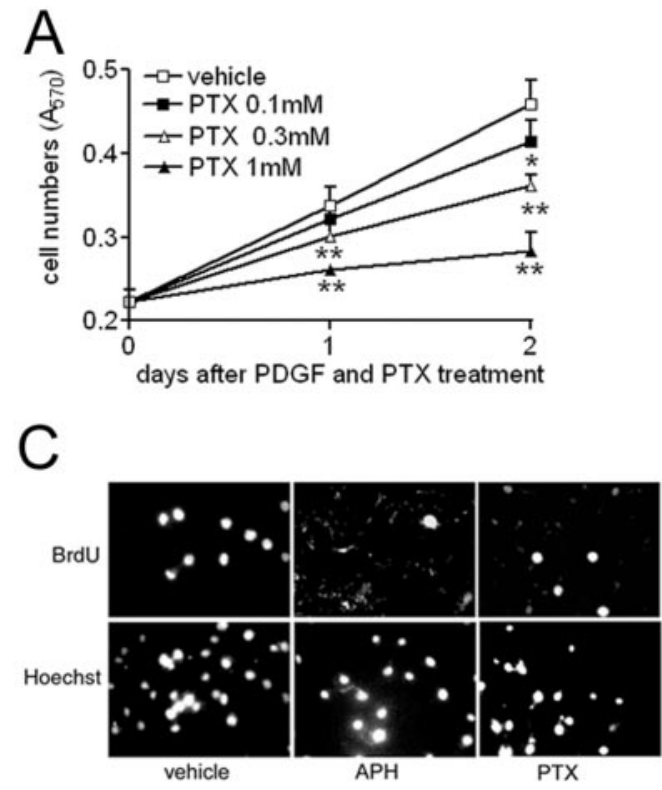

(\%)
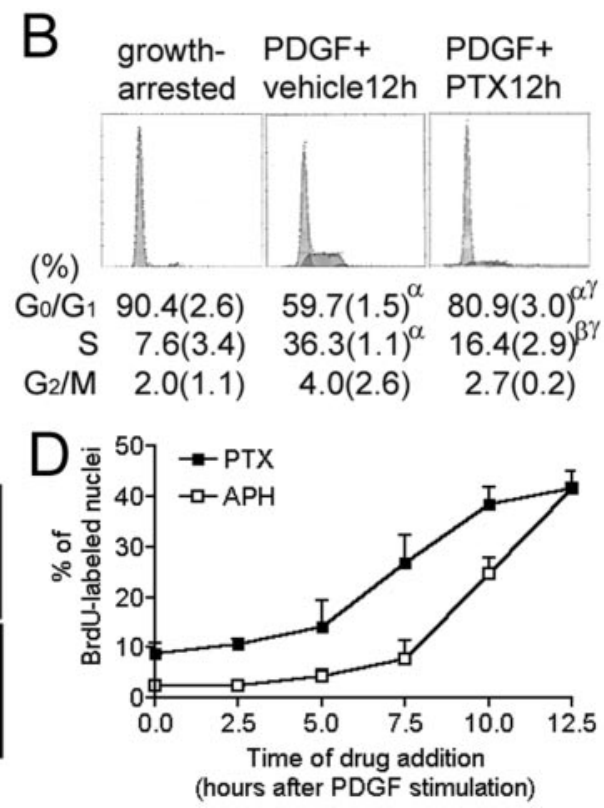

PKA Kinase Assay. PKA activity was assayed using the PepTag nonradioactive protein kinase assays kit (Promega). Total cellular extracts $(50 \mu \mathrm{g})$ were added into a reaction mixture containing $1 \mathrm{mM}$ ATP, $2 \mu \mathrm{g}$ of fluorescence-tagged PKA peptide substrates (Kemptide; LRRASLG). The catalytic subunit of cAMP-dependent protein kinase (PKA, $20 \mathrm{ng} /$ reaction), as a positive reaction control, was added in the parallel study. After incubation at $30^{\circ} \mathrm{C}$ for $30 \mathrm{~min}$, the samples were separated by agarose gel electrophoresis at neutral $\mathrm{pH}$. Phosphorylation alters Kemptide's net charge from +1 to -1 , allowing the phosphorylated peptide to be separated from the unphosphorylated one.

Miscellaneous Measurements. cAMP and cGMP concentrations were measured using enzyme immunoassay kits (Cayman Chemical, Ann Arbor, MI) as described previously (Chen et al., 1999c). The urinary creatinine and protein concentrations and lactate dehydrogenase levels were measured as described previously (Chen et al., 1999c; Lin et al., 2002).

Statistical Analysis. Statistical analyses were carried out using SPSS/Windows (SPSS Science, Chicago, IL) software on a personal computer. The statistical significance was evaluated by one-way analysis of variance using the Bonferroni correction application.

\section{Results}

PTX Inhibits $G_{1}$ Cell Cycle Progression in PDGF. Stimulated Mesangial Cells. To study the effect of PTX on the mesangial cell proliferation, growth-arrested cells were stimulated with PDGF in the presence of PTX or vehicle. Consistent with previous findings (Tsai et al., 1995), PTX caused a dose-dependent suppression of cell proliferation, as determined by MTT assay (Fig. 1A). To further characterize

Fig. 1.PTX inhibits $\mathrm{G}_{1}$ cell cycle progression in PDGF-stimulated mesangial cells. A, PTX causes a dose-dependent suppression of PDGF-stimulated mesangial cell proliferation. Growth-arrested cells were stimulated with $20 \mathrm{ng} / \mathrm{ml}$ of PDGF for 1 or 2 days in the presence of PTX or vehicle. Cell proliferation was determined by MTT assays and expressed as mean \pm S.D. from three independent experiments performed in quadruplicate. *, $p<$ 0.05 ; **, $p<0.01$ versus vehicle-treated. $\mathrm{B}$, PTX inhibits $\mathrm{G}_{1}$-to-S progression in PDGF-stimulated mesangial cells. Growth-arrested cells were stimulated with PDGF in the presence of PTX $(1 \mathrm{mM})$ or vehicle for $12 \mathrm{~h}$. Cell cycle profiles were determined by flow cytometric analysis and the percentage of cells in each phase of cell cycle was presented as mean (SD) from three independent experiments. $\alpha, p<0.01 ; \beta, p<0.05$ versus growth-arrested; $\gamma, p<0.01$ versus vehicle-treated. C, PTX prevents PDGF-stimulated mesangial cells from entering S phase. Growth-arrested cells were treated with PDGF in the combination of vehicle, APH $(25 \mu \mathrm{g} / \mathrm{ml})$, or PTX $(1 \mathrm{mM})$ for $12 \mathrm{~h}$. S phase entry was determined by BrdU labeling. Representative images of three independent experiments are shown at $400 \times$ magnification. D, PTX arrests PDGF-stimulated mesangial cells in mid- $\mathrm{G}_{1}$ phase about $2.5 \mathrm{~h}$ before the $\mathrm{G}_{1} / \mathrm{S}$ transition. Growth-arrested cells were stimulated with PDGF, and then PTX or APH was added at different times after PDGF stimulation. S phase entry was determined by BrdU labeling. The values shown are percentages of BrdU-labeled cells as mean \pm S.D. from three independent experiments, and more than 200 cells were counted for each experiment. 
this antiproliferative effect of PTX, cell cycle profiles were determined by flow cytometric analysis. When growth-arrested mesangial cells were stimulated with PDGF for $12 \mathrm{~h}$, $36.3 \%$ of cells had progressed into $\mathrm{S}$ phase. However, PTX significantly inhibited this PDGF-stimulated $\mathrm{G}_{1}$-to-S progression: only $16.4 \%$ of cells entered S phase (Fig. 1B). This antiproliferative effect of PTX could not be attributed to its cytotoxicity, because the cellular lactate dehydrogenase level (growth-arrested, $64 \pm 2.0 ;$ PDGF + vehicle, $63.0 \pm 1.7$; PDGF + $1 \mathrm{mM}$ PTX, $66.0 \pm 1.2 \mathrm{IU} / \mathrm{L}$ from three independent experiments) and the percentage of apoptotic cells examined by TUNEL assays (growth-arrested, $5.3 \pm 2.0 \%$; PDGF + vehicle, $6.2 \pm 2.1 \%$; PDGF $+1 \mathrm{mM}$ PTX, $6.0 \pm 2.8 \%$ from three independent experiments) were not altered.

Next, we determined the time point in $G_{1}$ at which PTX executed its inhibitory role. PTX was added at different times after PDGF stimulation, and then S phase entry was determined by BrdU labeling. As shown in Fig. 1, C and D, PTX prevented more than $80 \%$ of cells from entering $\mathrm{S}$ phase when added at or within $5 \mathrm{~h}$ after PDGF stimulation, but it was less effective when introduced at later time points. In a parallel study, aphidicolin (APH), a DNA polymerase $\alpha$ inhibitor, was used to determine the onset of $S$ phase after PDGF stimulation. Although APH prevented more than $90 \%$ of cells from entering $S$ phase when added at or within $7.5 \mathrm{~h}$ after PDGF stimulation, cells became refractory to APH treatment between 7.5 and $10 \mathrm{~h}$, which marked the $\mathrm{G}_{1} / \mathrm{S}$ boundary. Thus, the temporal difference in the sensitivities of cells to APH and PTX indicates that the latter arrested cells in the mid- $\mathrm{G}_{1}$ phase about $2.5 \mathrm{~h}$ before the $\mathrm{G}_{1} / \mathrm{S}$ transition. Overall, these data indicate that PTX suppresses cell proliferation by inhibiting the $\mathrm{G}_{1}$ cell cycle progression in PDGF-stimulated mesangial cells.

PTX Down-Regulates Cyclin D1 Expression and Rb Phosphorylation in PDGF-Stimulated Mesangial Cells. Cyclin D1 is a key regulator for early $\mathrm{G}_{1}$ phase progression in mesangial cells (Shankland et al., 1996; Terada et al., 1998; Lang et al., 2000;). Because PTX arrested PDGF-stimulated mesangial cells in mid- $G_{1}$ phase, we examined its effect on the regulation of cyclin D1 by PDGF. Growth-arrested mesangial cells were stimulated with PDGF in the presence or absence of PTX. The levels of cyclin D1 mRNA and protein were low in growth-arrested cells, but they increased with time and reached their highest levels at about 6 to $9 \mathrm{~h}$ after PDGF stimulation (Fig. 2). In PTX-treated cells, the levels of cyclin D1 mRNA and protein were lower than those of untreated cells at all time points after PDGF stimulation. Although the protein levels of Cdk4 were not changed, Cdk4 activity was decreased by PTX, as judged by the reduction in Rb phosphorylation at Ser780 (Fig. 2, B and C), a site specific for Cdk4 (Kitagawa et al., 1996). This inhibitory effect on Cdk4 activity was verified again by in vitro Cdk4 kinase assay, in which PTX significantly reduced the PDGF-stimulated phosphorylation of Rb at Ser780 (Fig. 4B). Together, our results identify cyclin D1 as a cell cycle target of PTX. By down-regulating the expression of cyclin D1, PTX blocks Rb phosphorylation and $\mathrm{G}_{1}$ cell cycle progression in PDGF-stimulated mesangial cells.

PTX Reduces Cyclin D1 Expression in Mesangial Cells of Rats with Acute Thy1 Glomerulonephritis. We previously reported that PTX attenuates mesangial cell proliferation in rats with acute Thy1 glomerulonephritis without interference with the induction of nephritis (Chen et al., 1999b). Other reports indicated that the cyclin D1-positive mesangial cells are increased on day 5 of acute Thy 1 glomerulonephritis, preceding the peak of the mesangial cell hyperplasia (Lang et al., 2000). We therefore examined the effect of PTX on cyclin D1 expression in mesangial cells of such nephritic rats. Consistent with our previous findings (Chen et al., 1999b), PTX attenuated the nephritis with $60 \%$ reduction of urinary protein excretion that was markedly increased in nephritic rats compared with the healthy control rats on day 5 (Fig. 3A). In agreement with a previous finding (Lang et al., 2000), the mRNA and protein levels of glomerular cyclin D1 in nephritic rats on day 5 were increased 2.4- and 2.3-fold, respectively, compared with the healthy control rats. However, these increases in cyclin D1 mRNA and protein were reduced by 46 and $43 \%$, respectively, in nephritic rats receiving PTX (Fig. 3, B and C). The number of cyclin D1/Thy1positive cells per glomerulus was increased from $9.5 \pm 2.9$ (control) to $27.1 \pm 5.7$ on day 5 of the nephritic rats and reduced to $15.6 \pm 5.4$ after PTX treatment (Fig. 3, D and E). These data indicate that, under both in vitro and in vivo situations, down-regulation of cyclin D1 accounts for at least one mechanism by which PTX suppresses mesangial cell proliferation.

PDGF Induces Cyclin D1 Expression in Mesangial Cells through PI3K/Akt Pathway. In certain cell types, both MAPK and PI3K pathways mediate the mitogenic effect of PDGF (Choudhury, 2001; Choudhury et al., 1997), and activation of either pathway has been reported to lead to an elevation of cyclin D1 expression (Cheng et al., 1998; Diehl et al., 1998; Jones and Kazlauskas, 2001). In agreement with these findings, we found that LY294002, a specific inhibitor PI3K, could down-regulate the expression of cyclin D1 mRNA and protein in PDGF-stimulated mesangial cells (Fig. 4A), which resulted in a decrease in $\mathrm{Cdk} 4$ kinase activity, as measured by in vitro Rb phosphorylation at Ser780 (Fig. 4B). In addition, we found that PD98059, a specific inhibitor for MEK1, could also inhibit the cyclin D1 expression and Cdk4
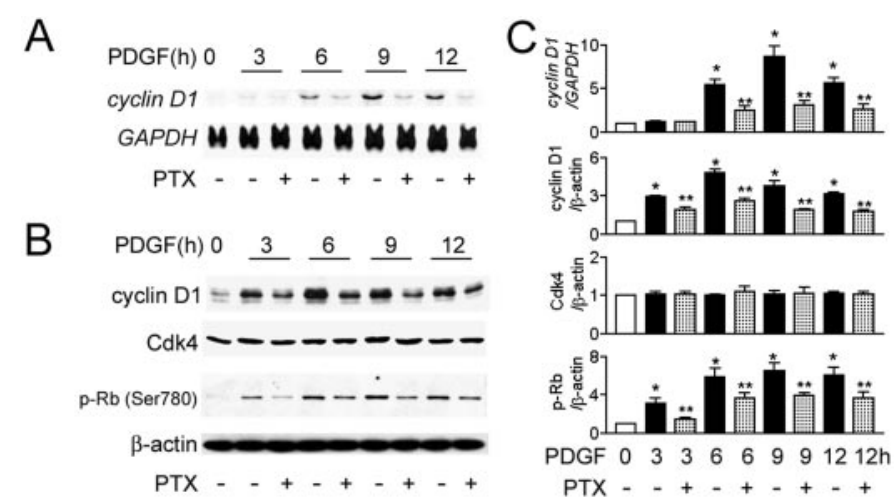

Fig. 2. PTX down-regulates cyclin D1 expression and Rb phosphorylation in PDGF-stimulated mesangial cells. A, PTX down-regulates cyclin D1 mRNA expression. Growth-arrested cells were stimulated with PDGF in the presence or absence of PTX for various times. The levels of cyclin D1 and GAPDH mRNAs were determined by Northern blot analysis. B, PTX down-regulates cyclin D1 protein expression and Rb phosphorylation. Total cellular extracts were prepared from cells and then subjected to Western blot analysis with various antibodies to cyclin D1, Cdk4, p-Rb (Ser780), and $\beta$-actin as indicated. Normalized signals from three independent experiments are shown in the bar charts as mean \pm S.D. (C). *, $p<0.01$ versus growth-arrested cells; **, $p<0.01$ versus PDGF-stimulated cells in the absence of PTX.

\section{을


activity in PDGF-stimulated mesangial cells (data not shown). One of the downstream signaling molecules of PI3K is the serine/threonine kinase Akt. To assess the role of Akt in PDGF-induced expression of cyclin D1, a dominant-negative mutant of Akt, HA-Akt-K179A, was introduced into mesangial cells. This mutant significantly reduced cyclin D1 induction by PDGF (Fig. 4C), indicating a role of Akt in this event. One of the established biological functions of Akt is the inhibition of apoptosis (Chen et al., 1998, 1999a). Apoptosis in mesangial cells after transfection of various Akt constructs for 2 days was examined by TUNEL assays, and the percentages of apoptosis (HA-Akt, $7.8 \pm 2.3 \%$; HA-Akt-K179A, $8.5 \pm$ $1.0 \%$ from three independent experiments) were not altered. Thus, our results confirm that both PI3K/Akt and MAPK pathways are responsible for the induction of cyclin D1 by PDGF in mesangial cells. Furthermore, overexpression of dominant-negative Akt in mesangial cells does not induce apoptosis.
A
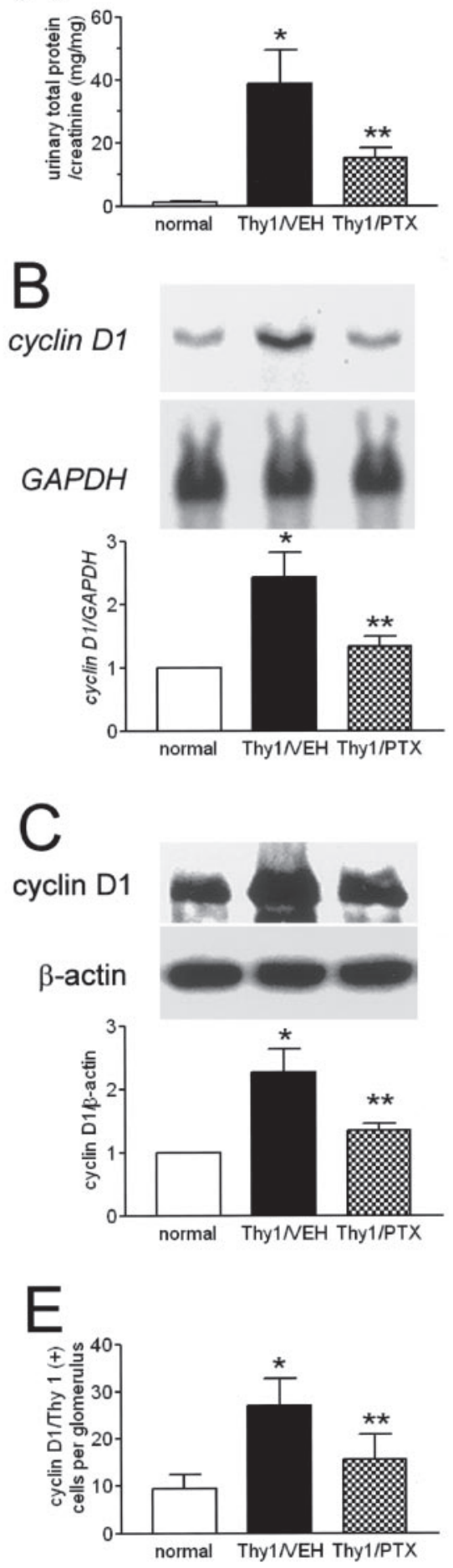
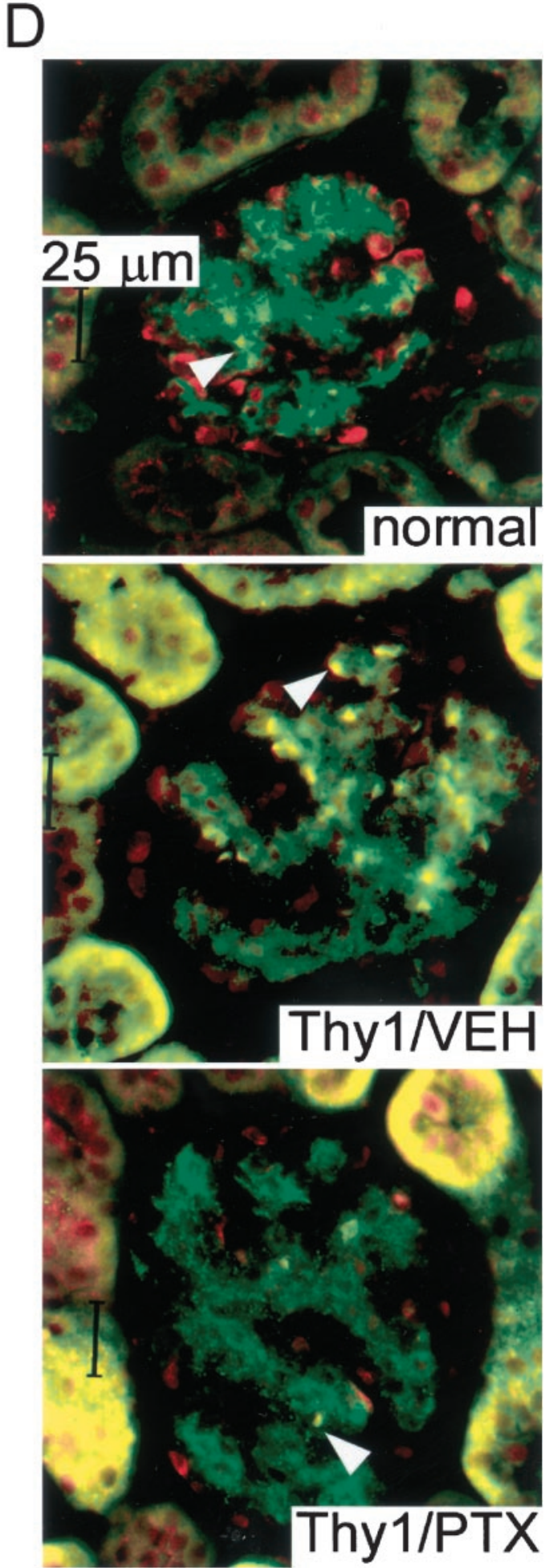

Fig. 3. PTX reduces cyclin D1 expression in mesangial cells of rats with acute Thy1 glomerulonephritis. A, PTX attenuates proteinuria in rats with acute Thy1 glomerulonephritis. The nephritic rats induced by anti-rat Thy 1 antibody were treated with vehicle (Thy1/VEH) or PTX (Thy1/PTX) from day 0 to day 5 ( $n=6$ for each group), whereas control rats received only PBS $(n=6)$. Urinary total protein/creatinine ratio was determined for each rat on day 5. Data are expressed as mean \pm S.D. for each group. B and C, PTX reduces glomerular cyclin D1 expression in rats with acute Thy 1 glomerulonephritis. Tota RNA and protein were prepared from glomeruli for each rat at day 5 and subjected to Northern blot (B) and Western bolt (C) analyses for cyclin D1. Representatives of Northern and Western blot analyses are one of six results in the parallel groups. Normalized signals are shown in the bar charts as mean \pm S.D. from the six rats in each group, respectively. $\mathrm{D}$ and $\mathrm{E}, \mathrm{PTX}$ reduces the numbers of mesangial cells with cyclin D1 expression in rats with acute Thy 1 glomerulonephritis. Double immunostaining of renal sections for each rat on day 5 for Thy 1 (green) and cyclin D1 (red) was examined by fluorescence microscopy. Mesangial cells expressing cyclin D1 are indicated by yellow staining (white arrowhead) (D). Calibration bars, $25 \mu \mathrm{m}$. The numbers of cyclin D1/Thy1 (+) cells per glomerulus were counted in 25 glomeruli per rat in high-power fields $(400 \times)$ and expressed as mean \pm S.D. for each group (E). *, $p<0.01$ versus control rats; $* * p<0.01$ versus Thy1/VEH. 
PTX Inhibits the Activation of Akt in PDGF-Stimulated Mesangial Cells. PTX has been shown to inhibit MAPK pathway (Pinzani et al., 1996; Peterson et al., 2002); however, its role in PI3K/Akt pathway has not been explored. As shown in Fig. 5, A and B, PDGF rapidly induced Akt phosphorylation at both Thr308 and Ser473, and this induction of Akt phosphorylation was significantly inhibited by PTX. In fact, the inhibitory effect of PTX on Akt phosphorylation was comparable with that caused by LY294002 (Fig. 5, $\mathrm{C}$ and $\mathrm{D}$ ). This down-regulation of Akt phosphorylation by PTX decreased Akt activity, as judged by reduced levels of GSK3 $\beta$ phosphorylation in vivo (Fig. 5 , A and B) and by an in vitro Akt kinase assay using GSK3 as an exogenous substrate (Fig. 5E). Thus, our results indicate that PTX interferes with PDGF signaling to Akt.

To determine the functional position of PTX along the PI3K/Akt pathway induced by PDGF, we transfected mesangial cells with the constitutively active mutant of PI3K (p110*). PTX reduced Akt phosphorylation triggered by constitutive activation of PI3K (Fig. 5F), implying an inhibitory role of PTX in the downstream event of PI3K. These studies indicate that PTX interferes with PDGF signaling to Akt by inhibiting an event downstream of PI3K.

PTX Blocks Akt Membrane Translocation, Leading to Cyclin D1 Down-Regulation. Translocation of Akt from cytosol to the plasma membrane via binding to 3 '-phosphoinositide, a product of PI3K, is crucial for its phosphorylation and activation by phosphoinositide-dependent kinase (Vanhaesebroeck et al., 1997; Scheid and Woodgett, 2001). We therefore examined the effect of PTX on the subcellular localization of Akt using cell fractionation analysis. In response to PDGF stimulation, a significant amount of Akt, accompanied by increased phosphorylation, was redistributed to the mesangial cell membrane (Fig. 6A). However, both membrane translocation and phosphorylation of Akt were drastically attenuated by PTX treatment (Fig. 6A). To further verify this result, we constructed a fusion protein, GFP-Akt, for visualizing its subcellular localization. Confocal microscopy revealed that both GFP-Akt and control GFP were mainly concentrated in the center of unstimulated mesangial cells. Upon PDGF stimulation, a significant portion of GFP-Akt was redistributed to the plasma membrane. This PDGF-induced translocation, notably, was markedly inhibited by PTX (Fig. 6B). However, neither PDGF nor PTX affected the distribution of control GFP. To demonstrate that this translocation blockage accounts for Akt inactivation by PTX, we transfected mesangial cells with HA-Akt-Myr, which is constitutively localized on the plasma membrane because of the addition of a myristoylation signal at its $\mathrm{N}$ terminus. As expected, HA-Akt-Myr markedly increased the

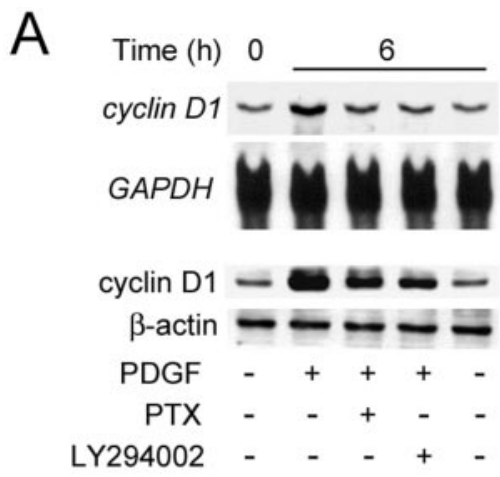

B

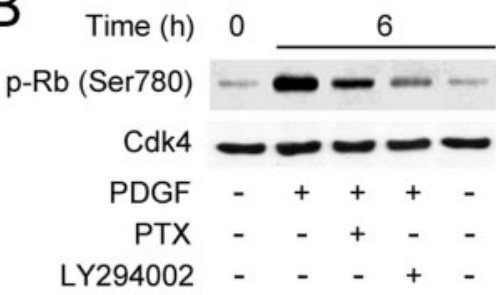

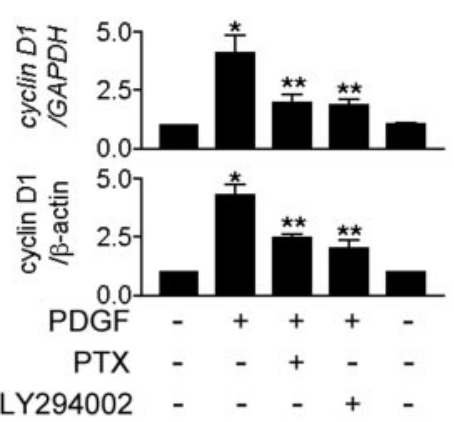

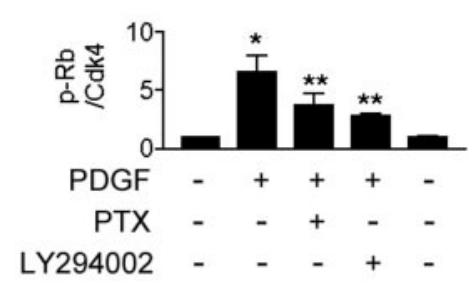

C

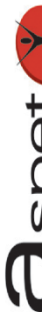

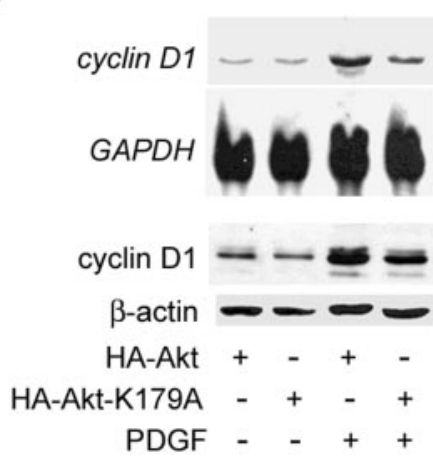
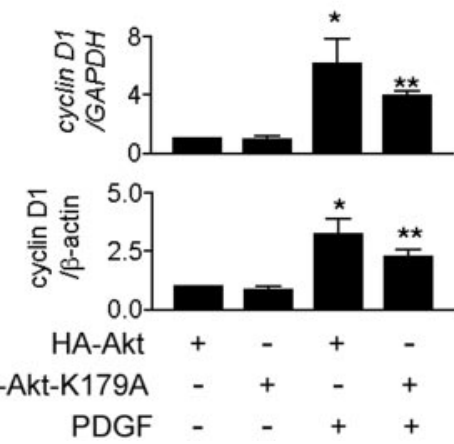

Fig. 4. PDGF induces cyclin D1 expression in mesangial cells through PI3K/Akt. A and B, PTX inhibits cyclin D1 expression and Cdk4 activity induced by PDGF, comparable with the effect of LY294002. Growth-arrested mesangial cells were treated with or without PDGF, PTX $(1 \mathrm{mM})$, and LY294002 $(50 \mu \mathrm{M})$ as indicated. Northern (A, top) and Western (A, bottom) blot analyses were performed as in Fig. 2. Cdk4 was immunoprecipitated from cell lysates and subjected to an in vitro kinase assay with GST-Rb as a substrate. The reaction mixtures were then used for Western blot analyses with an antibody to $\mathrm{p}-\mathrm{Rb}$ (Ser780) (B). Normalized signals from three independent experiments are shown in the bar charts as mean \pm S.D. (right). ${ }^{*}, p<0.01$ versus serum-deprived cells; **, $p<0.01$ versus PDGF-stimulated cells in the absence of PTX and LY294002. C, Akt is the downstream effector of PI3K in regulating cyclin D1 expression. Mesangial cells were transfected with either wild type (HA-Akt) or dominant-negative form (HA-Akt-K179A) of Akt, serum-starved for $24 \mathrm{~h}$, and then stimulated with or without PDGF for $6 \mathrm{~h}$. The expressions of cyclin D1 mRNA and protein were detected by Northern (top) and Western blot analyses (bottom). Normalized signals from four independent experiments are shown in the bar charts as mean \pm S.D. (right). $p<0.01$ versus HA-Akt-transfected cells stimulated without $(*)$ or with (**) PDGF. 
phosphorylation of GSK3 $\alpha / \beta$ in the absence of PDGF. More importantly, it prevented PTX-triggered Akt inactivation in PDGF-stimulated cells, whereas wild-type Akt (HA-Akt) did not display such a function (Fig. 6C). Thus, enforced targeting of Akt to cell membrane prevents the inhibition of Akt by PTX. These results provide the first evidence that PTX blocks the membrane translocation of Akt, thereby inhibiting its activation.

Next, we investigated whether the blockage of Akt membrane translocation accounts for the major mechanism by which PTX down-regulates cyclin D1 in PDGF-stimulated cells. Serum-deprived mesangial cells overexpressing consti-
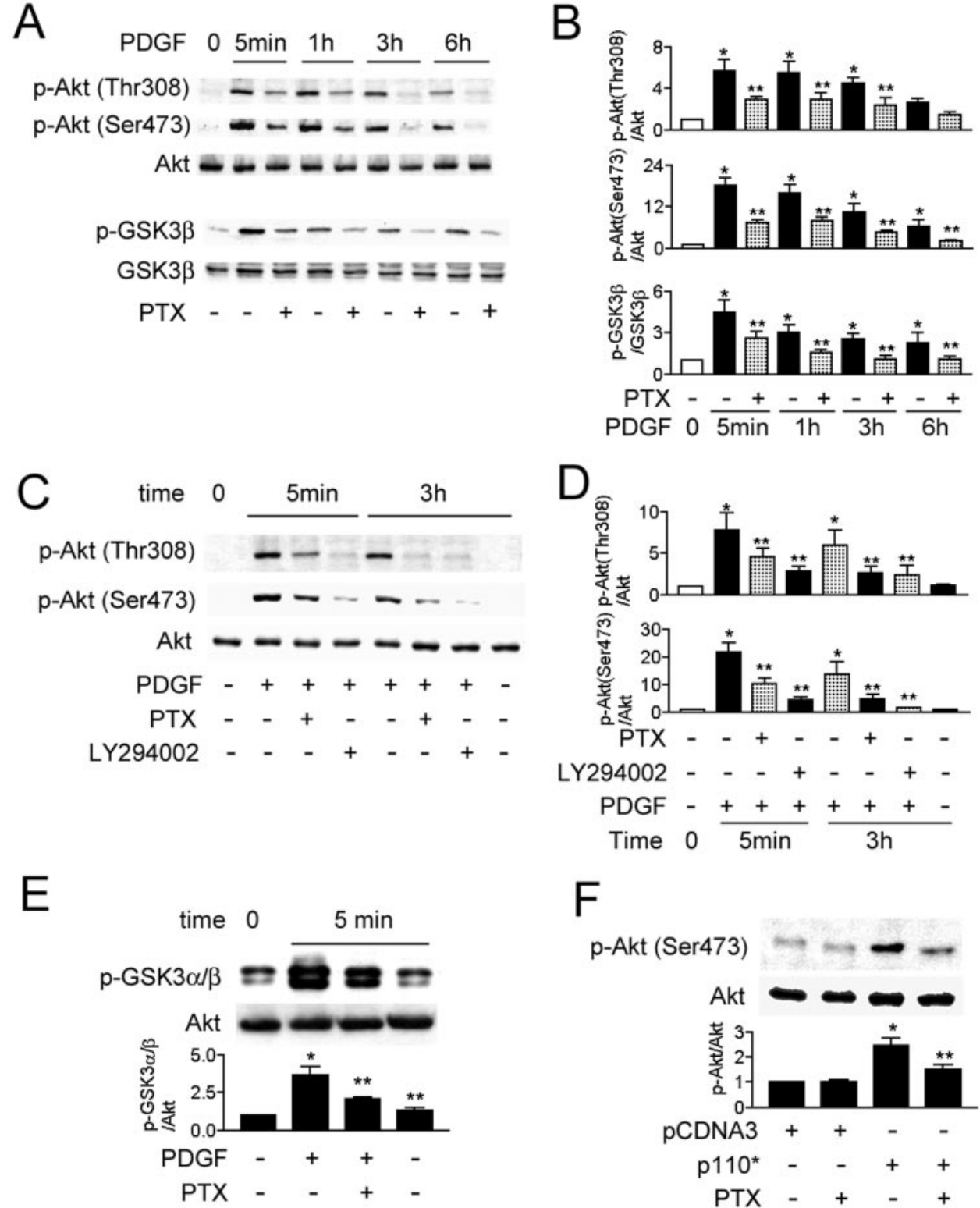

Fig. 5. PTX inhibits the activation of Akt in PDGF-stimulated mesangial cells. A and B, PTX causes a rapid blockage of PDGF signaling to Akt as well as its downstream GSK3 $\beta$. Growth-arrested mesangial cells were stimulated with PDGF in the presence or absence of PTX for various times. Total cellular extracts were subjected to Western blot analyses with various antibodies as indicated. Normalized signals from three independent experiments are shown in the bar charts as mean \pm S.D. (B). *, $p<0.01$ versus growth-arrested cells; **, $p<0.01$ versus PDGF-stimulated cells in the absence of PTX. C and D, PTX reduces Akt phosphorylation induced by PDGF, comparable with the effect of LY294002. Growth-arrested mesangial cells were treated with or without PDGF, PTX, and LY294002 as indicated. Western blot analyses were performed with various antibodies as indicated. Normalized signals from three independent experiments are shown in the bar charts as mean \pm S.D. (D). *, $p<0.01$ versus growth-arrested cells; **, $p<0.01$ versus PDGF-stimulated cells in the absence of PTX and LY294002. E, PTX inhibits PDGF-induced Akt activity. Growth-arrested mesangial cells were treated with or without PDGF and PTX for 5 min. Akt was immunoprecipitated by anti-Akt antibody and subjected to an in vitro kinase assay using GSK3 as a substrate. Phosphorylation of GSK3 in the kinase reactions was detected by Western blot with an antibody to p-GSK $3 \alpha / \beta$. Normalized signals from three independent experiments are shown in the bar charts as mean \pm S.D. *, $p<0.01$ versus growth-arrested cells; **, $p<0.01$ versus PDGF-stimulated cells in the absence of PTX. F, PTX reduces Akt phosphorylation triggered by constitutive activation of PI3K. Mesangial cells were transfected with pCDNA3 or constitutively active PI3K (p110*), serum-deprived for $24 \mathrm{~h}$, and then treated with or without PTX for $1 \mathrm{~h}$. Total cellular extracts were prepared and Western blot analysis was performed for p-Akt (Ser473) and Akt. Normalized signals from four independent experiments are shown in the bar charts as mean \pm S.D. ${ }^{*}, p<0.01$ versus pCDNA3-transfected cells; **, $p<0.01$ versus p110*-transfected cells in the absence of PTX. 
tutively membrane-localized Akt (HA-Akt-Myr) became refractory to PTX, whereas those overexpressing constitutively active PI3K (p110*) remained sensitive (Fig. 6D). These results not only confirm that PTX acts on Akt itself but also suggest that blockage of Akt membrane translocation is one of the mechanisms by which PTX down-regulates PDGFinduced cyclin D1.

PTX Inhibits Mesangial Cell Proliferation, Cyclin D1 Expression, and Akt Membrane Translocation through
PKA Activation. PTX has been known to be a nonselective phosphodiesterase inhibitor and to increase the intracellular cAMP levels (Chen et al., 1999c). As expected, PTX treatment of mesangial cells increased intracellular cAMP levels in a dosedependent manner (Fig. 7A), without affecting intracellular cGMP levels (data not shown). This elevation of cAMP level was accompanied by increases in both PKA activity and CREB phosphorylation, similar to the effect of PKA activators db-cAMP and FK/IBMX (Fig. 7, B and C). Furthermore, the CREB phos-
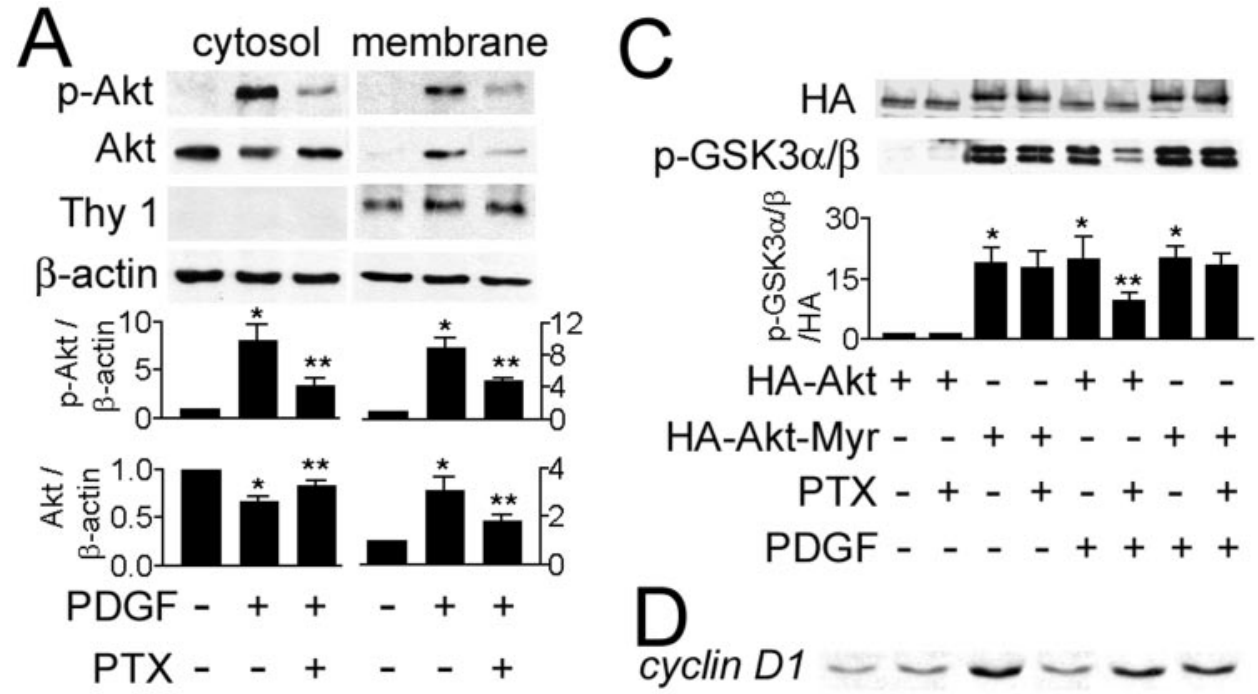

D
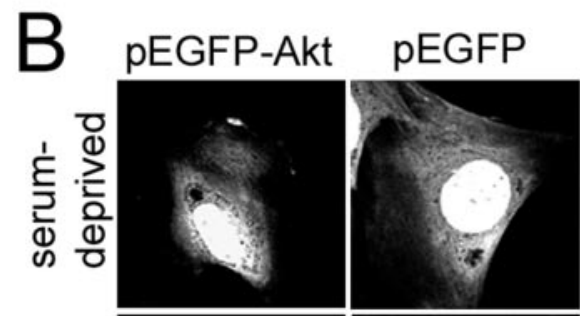

cyclin D1 - - - - -
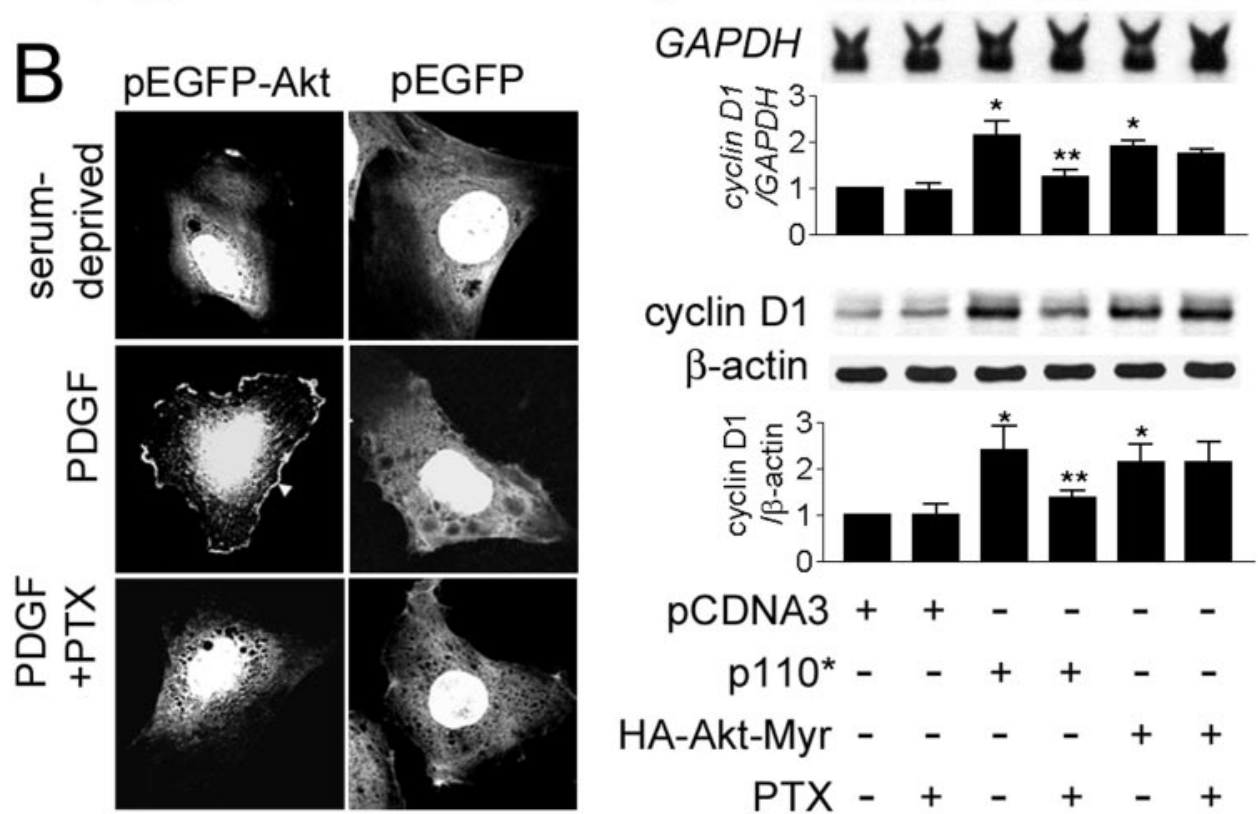

Fig. 6. PTX blocks Akt membrane translocation, leading to cyclin D1 down-regulation. A and B, PTX blocks Akt membrane translocation induced by PDGF. Growth-arrested mesangial cells were stimulated with PDGF for $5 \mathrm{~min}$ in the presence or absence of PTX. Cytosol and membrane fractions were prepared and Western blot analyses were performed with various antibodies as indicated in A. Normalized signals from three independent experiments are shown in the bar charts as mean \pm S.D. *, $p<0.01$ versus growth-arrested cells; **, $p<0.01$ versus PDGF-stimulated cells in the absence of PTX. Mesangial cells transfected with GFP-tagged Akt (pEGFP-Akt) or GFP control vectors (pEGFP) were serum-deprived for 24 h, and stimulated with PDGF for $5 \mathrm{~min}$ in the presence or absence of PTX. Cells were fixed by $4 \%$ paraformaldehyde and then examined under a laser-scanning confocal microscope. The membrane localization of GFP-Akt is indicated by an arrow in B. Shown are the representatives of three independent experiments. C, enforced membrane targeting of Akt prevents its inactivation by PTX. Mesangial cells transfected with wild type (HA-Akt) or constitutively membrane-localized Akt (HA-Akt-Myr) were serum-deprived for $24 \mathrm{~h}$, and stimulated with PDGF for 5 min in the presence or absence of PTX. Total cellular extracts precipitated with anti-HA antibody were subjected to kinase assays as described in Fig. 5C. Normalized signals from three independent experiments are shown in the bar charts as mean \pm S.D. ${ }^{*}, p<0.01$ versus serum-deprived HA-Akt-transfected cells; **, $p<0.01$ versus PDGF-stimulated HA-Akt-transfected cells in the absence of PTX. D, enforced membrane targeting of Akt overcomes PTX-induced cyclin D1 down-regulation. Mesangial cells transfected with pCDNA3, p110* or HA-Akt-Myr were serum-deprived for $24 \mathrm{~h}$, and then treated with or without PTX for $6 \mathrm{~h}$. Cyclin D1 expression was examined by Northern and Western blot analyses. Normalized signals from three independent experiments are shown in the bar charts as mean \pm S.D. ${ }^{*}, p<0.01$ versus pCDNA3-transfected cells; ${ }^{* *}, p<0.01$ versus p110*-transfected cells in the absence of PTX. 


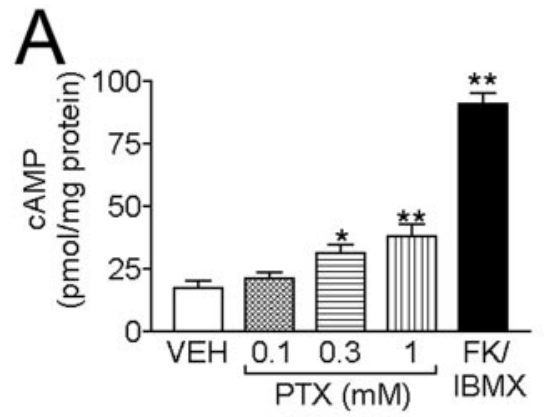

B

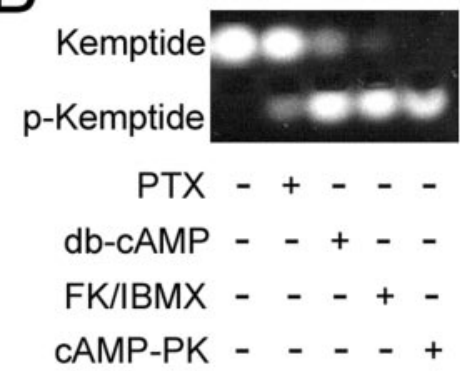

$\mathcal{C}$

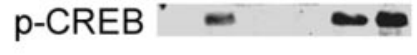

PTX - + + - -

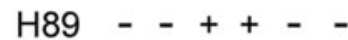

db-cAMP - - - + -

FK/IBMX - - - - +
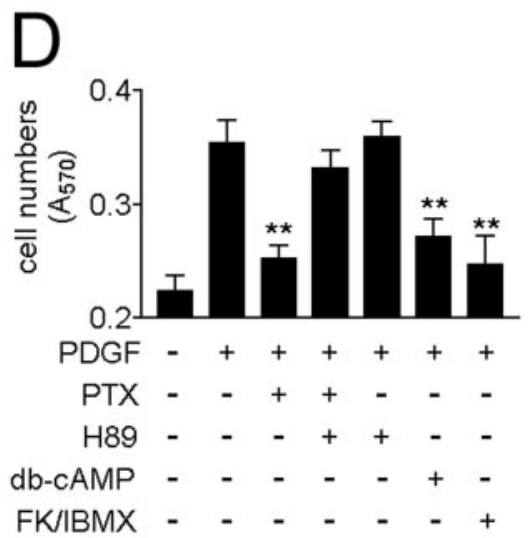

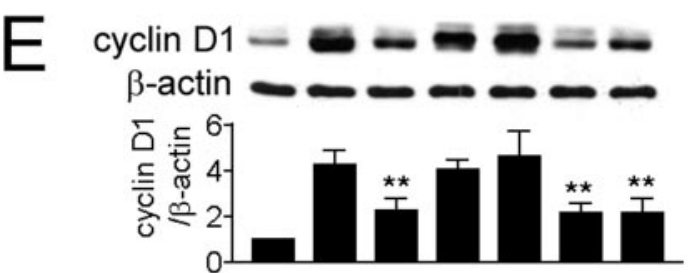

p-Akt(Ser473) - - - - - -

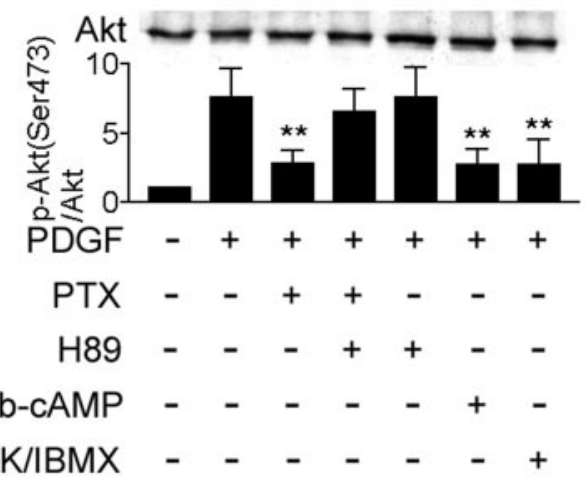

F
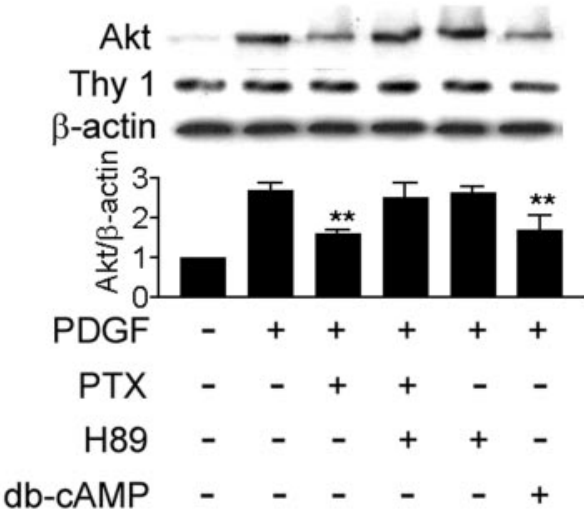

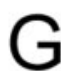

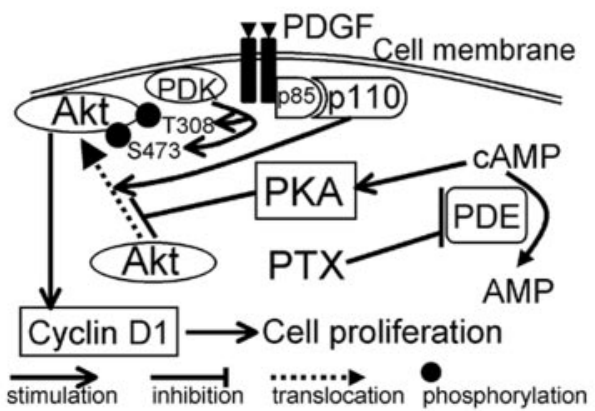

Fig. 7. PTX inhibits mesangial cell proliferation, cyclin D1 expression and Akt membrane translocation through PKA activation. A, PTX causes a dose-dependent increase in intracellular cAMP levels. Mesangial cells were treated with vehicle, PTX, or FK/IBMX $(20 \mu \mathrm{M} / 200 \mu \mathrm{M})$, cAMP concentrations per milligram of cellular protein were measured using enzyme immunoassay kits and expressed as mean \pm S.D. from three independent experiments performed in quadruplicate. ${ }^{*}, p<0.05 ; * *, p<0.01$ versus vehicle-treated. B, PTX activates PKA. Growth-arrested mesangial cells were treated with vehicle, PTX $(1 \mathrm{mM})$, FK/IBMX $(20 / 200 \mu \mathrm{M})$, or db-cAMP $(1 \mathrm{mM})$ for 15 min. Cellular extracts were used for assaying PKA activity, as determined by the phosphorylation of fluorescence-tagged Kemptide. The catalytic subunit of cAMP-dependent protein kinase (cAMP-PK, $20 \mathrm{ng}$ ) was used as a positive control. The reaction mixtures were then separated on an agarose gel at neutral pH. C, H89 blocks the phosphorylation of CREB induced by PTX. Growth-arrested mesangial cells were treated with PTX for 15 min in the presence or absence of H89 (1 $\mu \mathrm{M})$. Parallel study was performed with the treatment of db-cAMP or FK/IBMX. Nuclear extracts were prepared for Western blot analysis with anti-p-CREB antibody. D, PTX suppresses mesangial cell proliferation through PKA activation. Growth-arrested cells were stimulated with PDGF for 1 day in the presence of various agents as indicated. Cell proliferation was determined by MTT assay and expressed as mean \pm S.D. from three independent experiments performed in quadruplicate. **, $p<0.01$ versus vehicle-treated. E, PTX reduces cyclin D1 expression and Akt phosphorylation in PDGF-stimulated mesangial cells through PKA activation. Growth-arrested cells were stimulated with PDGF in the presence of various agents as indicated. Total cellular extracts were subjected to Western blot analyses with various antibodies as indicated. Normalized signals from 
phorylation induced by PTX could be completely prevented by PKA inhibitor H89 (Fig. 7C). Having confirmed that PTX is a PKA activator, we next examined whether the inhibitory effects of PTX on mesangial cell proliferation and PDGF signaling is mediated by PKA activation. Indeed, we found that H89 prevented PTX-triggered inhibition of cell proliferation, cyclin D1 expression, Akt phosphorylation, and membrane translocation in PDGF-stimulated mesangial cells, whereas H89 alone did not display any effect (Fig. 7, D, E, and F). To further demonstrate that PTX acts through PKA to affect cell proliferation, cyclin D1 expression, and Akt activation, we tested whether other PKA activators could mimic these effects of PTX. We found that db-cAMP or FK/IBMX could efficiently inhibit PDGF-stimulated cell proliferation, cyclin D1 expression, Akt phosphorylation, and membrane translocation to an extent similar to that of PTX (Fig. 7, D, E, and F). In summary, these studies not only indicate that the effect of PTX on mesangial cell proliferation and PDGF signal transduction is mediated by PKA but also reveal novel cross-talk between PKA and PI3K/ Akt pathway in mesangial cells (Fig. 7G).

\section{Discussion}

Considerable evidence indicates that mesangial cell proliferation is linked to glomerulosclerosis and that reduction of mesangial cell proliferation is indeed an effective inhibitor of renal disease progression (Johnson et al., 1992; Floege et al., 1999; Gilbert et al., 2001; Ostendorf et al., 2001). In previous studies, we have demonstrated that PTX significantly inhibits mesangial cell proliferation in vitro and in vivo, and it effectively attenuates the experimental mesangial proliferative glomerulonephritis and progressive chronic renal disease (Tsai et al., 1995; Chen et al., 1999b; Lin et al., 2002). We therefore propose that one possible mechanism by which PTX protects kidney from disease progression is linked to its effect against mesangial cell proliferation. However, the detail of this antiproliferative mechanism of PTX in mesangial cells is not known. In this study, we represent the first demonstration that PTX blocked PDGF-induced Akt activation in mesangial cells, thereby inhibiting cyclin D1 expression and cell proliferation.

The PI3K/Akt pathway has been reported to mediate the PDGF-induced mesangial cell proliferation (Choudhury et al., 1997; Choudhury, 2001). PTX has been shown not to interfere with the PI3K activity in other cell types (Pinzani et al., 1996). In this study, however, we demonstrated that PTX reduced Akt phosphorylation triggered by constitutive activation of PI3K in mesangial cells. We further demonstrated that PTX inhibited Akt activation through blocking its membrane translocation and that enforced membrane targeting of Akt could overcome the inhibition of Akt kinase activity by PTX. The membrane translocation of Akt is crucial for phosphorylation and activation by phosphoinositide-dependent kinase, which is usually constitutively active in various cell types, including mesangial cells (Alessi et al., 1997; Choudhury, 2001). How PTX blocks Akt membrane translo- cation is currently unclear. Nevertheless, the blockage of Akt membrane targeting without affecting PI3K activity has been reported for ceramide (Stratford et al., 2001; Bourbon et al., 2002). Additional experiments are required for determining whether PTX and ceramide block Akt membrane translocation through the same mode.

The PI3K/Akt pathway mediates the mitogenic effect of PDGF through regulating $G_{1}$ Cdk activity by promoting the synthesis of cyclin subunits, as well as decreasing the levels of Cdk inhibitors (Cheng et al., 1998; Diehl et al., 1998; Jones et al., 1999; Choudhury, 2001; Jones and Kazlauskas, 2001). In this study, we first confirmed that the PI3K/Akt pathway mediated PDGF signaling to cyclin D1 expression and Cdk4 activation in mesangial cells, which is in agreement with reports in the other cell types (Diehl et al., 1998; Jones et al., 1999; Jones and Kazlauskas, 2001). We further demonstrated that cyclin D1 induced in mesangial cells overexpressing a constitutively membrane-localized Akt was refractory to PTX, whereas that induced in cells overexpressing constitutively active PI3K remained sensitive. This novel finding indicates that blockage of Akt membrane translocation is one of the mechanisms by which PTX down-regulates PDGF-induced cyclin D1. Although Akt has been well documented as a pro-survival protein, we found that neither dominant-negative interference nor PTX-induced inhibition of its activity caused apoptosis in rat mesangial cells, which is in consistent with a previous report (Choudhury, 2001). Among the in vivo substrates of Akt, GSK3 $\beta$ is probably the most important in regulating its cell cycle effects. Inhibitory phosphorylation of GSK3 $\beta$ by Akt prevents its phosphorylation of cyclin D1, thereby suppressing cyclin D1 proteolytic cleavage (Diehl et al., 1998). Accordingly, we observed that PTX attenuated PDGF-induced GSK3 $\beta$ phosphorylation, which will cause cyclin D1 phosphorylation and degradation. In addition to the inhibitory effect on GSK3 $\beta$-induced cyclin D1 degradation, Akt has been shown to induce cyclin D1 transcription by phosphorylating and repressing FKHR, a member of forkhead transcription factors (Hutchinson et al., 2001). Whether regulation of cyclin D1 expression by Akt is caused by phosphorylation of GSK3 $\beta$ and forkhead transcription factors has yet to be established in mesangial cells.

In addition to the PI3K/Akt pathway, we also confirmed that the MAPK pathway mediated the regulation of cyclin D1 expression in PDGF-stimulated mesangial cells, which has been well demonstrated in the other cell types (Cheng et al., 1998). PTX, indeed, has been shown to inhibit Raf-1/extracellular signal-regulated kinase and Jun N-terminal kinase pathways, thereby suppressing cell proliferation (Pinzani et al., 1996; Ciullo et al., 2001; Peterson et al., 2002). Accordingly, PTX is a potent inhibitor of mesangial cell proliferation by blocking the multiple postreceptor signaling pathways of PDGF.

In this study, we found that the antiproliferative effect of PTX on PDGF-stimulated mesangial cells was PKA-dependent, which is in agreement with findings observed from

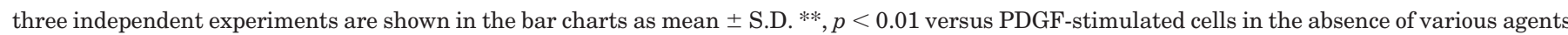

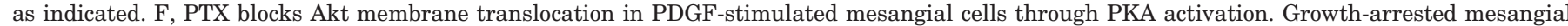

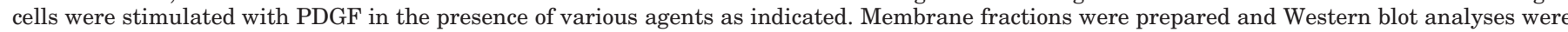

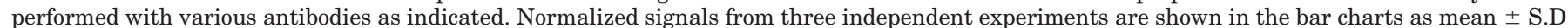

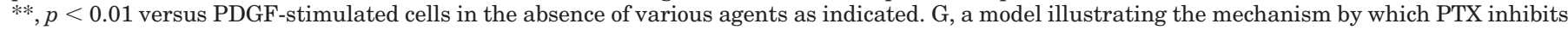
mesangial cell proliferation, cyclin D1 expression, and Akt membrane translocation through PKA. 
other cell types (Pinzani et al., 1996; Chen et al., 1999c; Mei et al., 2002). In addition to PTX, PKA is also involved in adrenomedullin-induced antiproliferative effect on PDGFstimulated mesangial cells (Chini et al., 1995; Kohno et al., 1999), indicating a cross-talk between PKA and PDGF signaling pathways. We thus dissected the mechanism of this cross-talk and found that the inhibitory effect of PTX on Akt activation and cyclin D1 expression in PDGF-stimulated mesangial cells was again PKA-dependent. These findings, in conjunction with the demonstration that PTX interferes with Akt membrane translocation, strongly suggest that PKA blocks PDGF signaling by inhibiting Akt membrane translocation. In accordance with our findings, stimulation of PKA was previously found to mediate the inhibitory effect of cAMP on Akt activation in HEK293 cells (Mei et al., 2002). Therefore, blockage of Akt membrane translocation by PKA might not be restricted to the mesangial cell system used in this study. However, the effect of cAMP on cell proliferation and Akt activation has been shown to be cell type-specific (Wang et al., 2001; Mei et al., 2002). Multiple cAMP-mediated pathways exist, and only some are PKA-dependent. For instance, cAMP has been reported to inhibit PI3K/Akt activation in $\mathrm{C} 6$ glioma cells through Rap1 inhibition, a mechanism independent of PKA (Wang et al., 2001).

Almost all forms of kidney diseases with renal failure progression are characterized by cell proliferation, inflammation, and fibrosis (Klahr et al., 1988; Chen et al., 1999b; Lin et al., 2002). Our previous studies have shown that PTX, in addition to its antiproliferative effect on glomerular mesangial cells and macrophage, effectively reduces inflammatory cytokine expression, inflammatory mononuclear cell infiltration, and extracellular matrix accumulation (Chen et al., 1999b; Lin et al., 2002), although the detailed mechanism by which PTX inhibits inflammation and fibrosis remains to be determined. These additive effects may explain the effectiveness of PTX in the reduction of urinary protein excretion, an indicator of glomerulonephritis severity. Furthermore, PTX has been shown to cause indiscernible cytotoxicity in this study as well as little adverse effect in clinical application (Navarro et al., 1999; Duclous et al., 2001), indicating that PTX is a potent and safe drug for kidney disease treatment.

In conclusion, our results indicate that PTX, acting through PKA, interferes with PDGF signaling to Akt activation by blocking Akt membrane translocation, thereby inhibiting cyclin D1 expression and mesangial cell proliferation. These findings may partly explain the mechanism by which PTX attenuates experimental mesangial proliferative renal disease.

\section{Acknowledgments}

We are grateful to Prof. Wan-Yu Chen for his helpful discussion while preparing this manuscript, Chin-Ching Yang and Kuo-Tong Huang for their technical assistance, and the Third Common Room in Department of Medical Research and the Core Laboratory for Confocal Scanning Microscope for the support of instruments.

\section{References}

Alessi DR, Deak M, Casamayor A, Caudwell FB, Morrice N, Norman DG, Gaffney P, Reese CB, MacDaugall CB, Harbison D, et al. (1997) Phosphoinositide-dependent protein kinase-1 (PDK1): structural and functional homology with the Drosophila DSTPK61 kinase. Curr Biol 7:776-789.

Bourbon NA, Sandirasegarane L, and Kester M (2002) Ceramide-induced inhibition of Akt is mediated through protein kinase Czeta: implications for growth arrest. J Biol Chem 277:3286-3292.
Chen RH, Chang MC, Su YH, Tsai YT, and Kuo ML (1999a) Interleukin-6 inhibits transforming growth factor- $\beta$-induced apoptosis through the phosphatidylinositol 3-kinase/Akt and signal transducers and activators of transcription 3 pathways. $J$ Biol Chem 274:23013-23019.

Chen RH, Su YH, Chuang RLC, and Chang TY (1998) Suppression of transforming growth factor- $\beta$-induced apoptosis through a phosphatidylinositol 3-kinase/Aktdependent pathway. Oncogene 17:1959-1968.

Chen YM, Chien CT, Hu-Tsai MI, Wu KD, Tsai CC, Wu MS, and Tsai TJ (1999b) Pentoxifylline attenuates experimental mesangial proliferative glomerulonephritis. Kidney Int 56:932-943.

Chen YM, Lin SL, Chen CW, Chiang WC, Tsai TJ, and Hsieh BS (2003) Tumor necrosis factor- $\alpha$ stimulates fractalkine production by mesangial cells and regulates monocytes transmigration: down-regulation by cAMP. Kidney Int 63:474486.

Chen YM, Wu KD, Tsai TJ, and Hsieh BS (1999c) Pentoxifylline inhibits PDGFinduced proliferation of and TGF-beta-stimulated collagen synthesis by vascular smooth muscle cells. J Mol Cell Cardiol 3:773-783.

Cheng M, Sexl V, Sherr CJ, and Roussel MF (1998) Assembly of cyclin D-dependent kinase and titration of $\mathrm{p} 27^{\text {Kip } 1}$ regulated by mitogen-activated protein kinase kinase (MEK1). Proc Natl Acad Sci USA 95:1091-1096.

Chini EN, Choi E, Grande JP, Burnett JC, and Dousa TP (1995) Adrenomedullin suppresses mitogenesis in rat mesangial cells via cAMP pathway. Biochem Bio phys Res Commun 215:868-873.

Choudhury GG (2001) Akt serine threonine kinase regulates platelet-derived growth factor-induced DNA synthesis in glomerular mesangial cells: regulation of c-fos and $27^{\text {Kip } 1}$ gene expression. J Biol Chem 276:35636-35643.

Choudhury GG, Karamitsos C, Hernandez J, Gentilini A, Bardgette J and Abboud HE (1997) PI-3-kinase and MAPK regulate mesangial cell proliferation and migration in response to PDGF. Am J Physiol 273:F931-F938.

Ciullo I, Diez-Roux G, Di Domenico M, Migliaccio A, and Avvedimento EV (2001) cAMP signaling selectively influences Ras effector pathways. Oncogene 20:11861192.

Diehl JA, Cheng M, Roussel MF, and Sherr CJ (1998) Glycogen synthase kinase-3 $\beta$ regulates cyclin D1 proteolysis and subcellular localization. Genes Dev 12:34993511.

Duclous D, Bresson-Vautrin C, and Chalopin JM (2001) Use of pentoxifylline in membranous nephropathy. Lancet 357:1672-1673.

Floege J, Ostendorf T, Janssen U, Gurg M, Radeke HH, Vargeese C, Gill SC, Green LS, and Janjic N (1999) Novel approach to specific growth factor inhibition in vivo: antagonism of platelet-derived growth factor in glomerulonephritis by aptamers. Am J Pathol 154:169-179.

Gilbert RE, Kelly DJ, Mckay T, Chadban S, Hill PA, Cooper ME, Atkins RC, and Nikolic-Paterson DJ (2001) PDGF signal transduction inhibition ameliorates experimental mesangial proliferative glomerulonephritis. Kidney Int 59:1324-1332.

Hutchinson J, Jin J, Cardiff RD, Woodgett JR, and Muller WJ (2001) Activation of Akt (protein kinase B) in mammary epithelium provides a critical cell survival signal required for tumor progression. Mol Cell Biol 21:2203-2212.

Johnson RJ, Raines EW, Floege J, Yoshimura A, Pritzl P, Alpers C, and Ross R (1992) Inhibition of mesangial cell proliferation and matrix expansion in glomerulonephritis in the rat by antibody to platelet-derived growth factor. J Exp Med 175:1413-1416.

Jones SM and Kazlauskas A (2001) Growth-factor-dependent mitogenesis requires two distinct phases of signaling. Nat Cell Biol 3:165-172.

Jones SM, Klinghoffer R, Prestwich GD, Toker A, and Kazlauskas A (1999) PDGF induces an early and a late wave of PI3K activity and only the late wave is required for progression through G1. Curr Biol 9:512-521.

Kitagawa M, Higashi H, Jung HK, Suzuki-Takahashi I, Ikeda M, Tamai K, Kato J, Segawa K, Yoshida E, Nishimura S, et al. (1996) The consensus motif for phosphorylation by cyclin D1-Cdk4 is different from that for phosphorylation by cyclin A/E-Cdk2. EMBO (Eur Mol Biol Organ) J 15:7060-7069.

Klahr S, Schreiner G, and Ichikawa I (1988) The progression of renal disease. N Engl J Med 318:1657-1666.

Kohno M, Yasunari K, Minami M, Kano H, Maeda K, Mandal AK, Inoki K, Haneda $\mathrm{M}$, and Yoshikawa J (1999) Regulation of rat mesangial cell migration by plateletderived growth factor, angiotensin II and adrenomedullin. J Am Soc Nephrol 10:2495-2502.

Lang S, Hartner A, Sterzel RB, and Schocklmann HO (2000) Requirement of cyclin D1 in mesangial cell mitogenesis. J Am Soc Nephrol 11:1398-1408.

Lin SL, Chen YM, Chien CT, Chiang WC, Tsai CC, and Tsai TJ (2002) Pentoxifylline attenuated the renal disease progression in rats with remnant kidney. J Am Soc Nephrol 13:2916-2929.

Mei FC, Qiao J, Tsygankova OM, Meinkoth JL, Quilliam LA, and Cheng X (2002) Differential signaling of cyclic AMP: opposing effects of exchange protein directly activated by cyclic AMP and cAMP-dependent protein kinase on protein kinase B activation. $J$ Biol Chem 277:11497-11504.

Navarro JF, Mora C, Rivero A, Gallego E, Chahin J, Macia M, Mendez ML, and Garcia J (1999) Urinary protein excretion and serum tumor necrosis factor in diabetic patients with advanced renal failure: effects of pentoxifylline administration. Am J Kidney Dis 33:458-463.

Ostendorf T, Kunter U, Grone HJ, Bahlmann F, Kawachi H, Shimizu F, Koch KM, Janjic N, and Floege J (2001) Specific antagonism of PDGF prevents renal scarring in experimental glomerulonephritis. J Am Soc Nephrol 12:909-918.

Peterson TC, Peterson MR, Robertson HA, During M, and Dragunow M (2002) Selective down-regulation of $c$-jun gene expression by pentoxifylline and c-jun antisense interrupts platelet-derived growth factor signaling: pentoxifylline inhibits phosphorylation of c-Jun on serine 73. Mol Pharmacol 61:1476-1488.

Pinzani M, Marra F, Caligirui A, DeFranco R, Gentilini A, Failli P, and Gentilini P (1996) Inhibition by pentoxifylline of extracellular signal-regulated kinase activation by platelet-derived growth factor in hepatic stellate cells. Br J Pharmacol 119:1117-1124. 
Scheid MP and Woodgett JR (2001) PKB/AKT: functional insights from genetic models. Nat Rev Mol Cell Bio 2:760-768.

Schindler T, Bornmann W, Pellicena P, Miller WT, Clarkson B, and Kuriyan J (2000) Structural mechanism for STI-571 inhibition of Abelson tyrosine kinase. Science (Wash DC) 289:1938-1942.

Shankland SJ, Hugo C, Coats SR, Nangaku M, Pichler RH, Gordon KL, Pippin J, Roberts JM, Couser WG, and Johnson RJ (1996) Changes in cell-cycle protein expression during experimental mesangial proliferative glomerulonephritis. Kidney Int 50:1230-1239.

Shankland SJ, Pippin J, Flanagan M, Coats SR, Nangaku M, Gordon KL, Roberts JM, Couser WG, and Johnson RJ (1997) Mesangial cell proliferation mediated by $\mathrm{PDGF}$ and bFGF is determined by levels of the cyclin kinase inhibitor $\mathrm{p} 27^{\text {Kip } 1}$. Kidney Int 51:1088-1099.

Stratford S, DeWald DB, and Summers SA (2001) Ceramide dissociates 3'phosphoinositide production from pleckstrin homology domain translocation. Biochem $J$ 354:359-368.

Tamura K, Kanaoka Y, Jinno S, Nagata A, Ogiso Y, Shimizu K, Hayakawa T, Nojima $\mathrm{H}$, and Okayama H (1993) Cyclin G: a new mammalian cyclin with homology to fission yeast Cig1. Oncogene 8:2113-2118.
Terada Y, Inoshita S, Nakashima O, Yamada T, Tamamori M, Ito H, Sasaki S, and Marumo F (1998) Cyclin D1, p16 and retinoblastoma gene regulate mitogenic signaling of endothelin in rat mesangial cells. Kidney Int 53:76-83.

Tsai TJ, Lin RH, Chang CC, Chen YM, Chen CF, Ko FN, and Teng CM (1995) Vasodilator agents modulate rat glomerular mesangial cell growth and collagen synthesis. Nephron 70:91-100.

Vanhaesebroeck B, Leevers SJ, Panayotou G, and Waterfield MD (1997) Phosphoinositide 3-kinases: a conserved family of signal transducers. Trends Biochem Sci 22:267-272.

Wang L, Liu F, and Adamo ML (2001) Cyclic AMP inhibits extracellular signalregulated kinase and phosphatidylinositol 3-kinase/Akt pathways by inhibiting Rap1. J Biol Chem 276:37242-37249.

Address correspondence to: Dr. Tun-Jun Tsai, Department of Internal Medicine, National Taiwan University Hospital, 7, Chung-Shan South Road, Taipei, Taiwan. E-mail: paul@ha.mc.ntu.edu.tw 